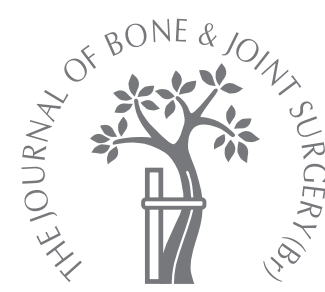

\title{
Construct validity of the Enneking score for measuring function in patients with malignant or aggressive benign tumours of the upper limb
}

T. Wada,

A. Kawai,

K. Ihara,

M. Sasaki,

T. Sonoda,

T. Imaeda,

T. Yamashita

From Sapporo

Medical University,

Sapporo, Japan

T. Wada, MD, Associate

Professor

M. Sasaki, MD, Orthopaedic Surgeon

T. Yamashita, MD, Professor Department of Orthopaedic Surgery

T. Sonoda, DDS, Instructor Department of Public Health

Sapporo Medical University,

South 1, West 16, Chuo-ku,

Sapporo, Hokkaido 060-8543,

Japan.

A. Kawai, MD, Head

Department of Orthopaedic

Surgery

National Cancer Centre

Hospital, 5-1-1, Tsukiji, Chuo-

ku, Tokyo 104-0045, Japan.

K. Ihara, MD, Chief

Department of Orthopaedic

Surgery

Kannmon Medical Center, 1-1-

1. Ushiroda-cho, Shimonoseki,

Yamaguchi, 751-8501, Japan.

- T. Imaeda, MD, Assistant

Professor

Department of Public Heath

Fujita Health University Schoo

of Medicine, 1-98

Dengakugakkubo,

Kutsukakecho, Toyoake, Aichi

470-1192, Japan.

Correspondence should be sent

to Dr T. Wada; e-mail:

twada@sapmed.ac.jp

(c)2007 British Editorial Society of Bone and Joint Surgery doi:10.1302/0301-620X.89B5 $18498 \$ 2.00$

$J$ Bone Joint Surg $[B r]$ 2007;89-B:659-63.

Received 7 August 2006;

Accepted after revision

9 January 2007

\begin{abstract}
We evaluated the construct validity of the Musculoskeletal Tumour Society rating scale (Enneking score) as a functional measure for patients with sarcoma involving the upper limb. We compared the Enneking score by examining the correlation between two patientderived outcome measures, the Disability of the Arm, Shoulder, and Hand (DASH) questionnaire and the Medical Outcomes Study Short Form-36 (SF-36) as indicators of functional status in $\mathbf{4 0}$ patients with malignant or aggressive benign bone and soft-tissue tumours of the upper limb who had undergone surgical treatment.

The frequency distributions were similar among the three scoring systems. As for the validity, Spearman's rank correlation coefficient of the Enneking score to the DASH questionnaire was $\mathbf{- 0 . 7 9}$ and that of the Enneking to the SF-36 subscales ranged from 0.38 to 0.60. Despite being a measure from the surgeon's perspective, the Enneking score was shown to be a valid indicator of physical disability in patients with malignant or aggressive benign tumours of the upper limb and reflected their opinion.
\end{abstract}

The function of the arm in a patient with musculoskeletal sarcoma has been assessed widely using the Musculoskeletal Tumour Society rating scale (Enneking score) which was originally described by Enneking in $1987^{1}$ and also by Enneking et $\mathrm{al}^{2}$ in 1993. This score is based on an analysis of factors pertinent to the patient as a whole and of those specific to the affected upper limb. Each of these is assigned a value of 0 to 5 points (maximum overall score, 30 points) on the basis of established criteria. To date there has been no study which has shown the Enneking score to be valid as an outcome measure for patients with sarcoma affecting the arm.

Recently, attention has been focused on the impact of a disorder on the ability to function in daily life with a move towards measures of health-related quality of life, both generic and disease- or domain-specific. These often use self-administered questionnaires. Patients with sarcoma involving a limb have had little attention directed towards evaluating the functional outcome from their perspective. ${ }^{3}$ The Enneking score is a disease-specific but physicianbased measure. Potential existing patientbased measures for patients with sarcoma of the arm include region-specific functional questionnaires, the Disabilities of the Arm, Shoulder, and Hand (DASH) questionnaire ${ }^{4,5}$ and general health-status questionnaires such as the Medical Outcomes Study Short Form-36 (SF-36). ${ }^{6,7}$ Previous reports have validated the DASH score for patients with disorders of the upper $\operatorname{limb} b^{5,8,9}$ and the SF-36 for those with musculoskeletal complaints. ${ }^{10,11}$

Our aim was to determine the construct validity of the Enneking score used to measure disability and symptoms of patients with sarcoma of the arm. Construct validity indicates the degree to which a scoring system is associated with other measures that are hypothesised to have a specific relationship with the system. Testing of construct validity builds confidence in a scoring system. We examined the correlation of the Enneking score with the DASH and SF-36 scores to describe a series of patients who had surgery for sarcoma of the arm. The underlying hypothesis was that the three different measures would perform in a similar manner (i.e. be correlated with each other) since they were conceptually similar in their goals and design.

\section{Patients and Methods}

A series of 40 patients with malignant or aggressive benign bone and soft-tissue tumours of the upper limb, who had undergone surgery and were scheduled to be seen in three co-operative musculoskeletal oncology centres (Sapporo Medical University Hospital, Sapporo National Cancer Centre Hospital, Tokyo 
Table I. A modified Enneking ${ }^{12}$ functional scoring system

\begin{tabular}{|c|c|c|c|c|c|c|}
\hline Score & Pain & Function & Emotional acceptance & Hand position & Manual dexterity & Lifting ability \\
\hline 5 & No pain & Not restricted & Enthused & Unlimited & No limitations & Normal load \\
\hline 4 & Intermediate & Intermediate & Intermediate & Intermediate & Intermediate & Intermediate \\
\hline 3 & Modest/non-disabling & $\begin{array}{l}\text { Recreational } \\
\text { restriction }\end{array}$ & Satisfied & $\begin{array}{l}\text { Not above shoulder/ } \\
\text { no prosupination }\end{array}$ & $\begin{array}{l}\text { Loss of fine } \\
\text { movements }\end{array}$ & Limited \\
\hline 2 & Intermediate & Intermediate & Intermediate & Intermediate & Intermediate & Intermediate \\
\hline 1 & $\begin{array}{l}\text { Moderate/intermittently } \\
\text { disabling }\end{array}$ & $\begin{array}{l}\text { Partial occupational } \\
\text { restriction }\end{array}$ & Accepts & Not above waist & Cannot pinch & Helping only \\
\hline 0 & $\begin{array}{l}\text { Severe/continuously } \\
\text { disabling }\end{array}$ & $\begin{array}{l}\text { Total occupational } \\
\text { restriction }\end{array}$ & Dislikes & None & Cannot grasp & Cannot help \\
\hline
\end{tabular}

Table II. Details of outcome measures used to assess function in patients with sarcoma of the upper limb

\begin{tabular}{|c|c|c|c|c|c|}
\hline Outcome measure* & Who evaluates? & Dimension/number of items & Scaling of responses & Ease of scoring & $\begin{array}{l}\text { Usable questionnaires } \\
(\mathrm{n}=40)\end{array}$ \\
\hline Enneking & Physician & $\begin{array}{l}\text { Function, pain, emotional } \\
\text { acceptance, hand position, } \\
\text { dexterity, lifting ability }\end{array}$ & 5-point scale of each arm & Easy & $40(100)$ \\
\hline DASH (JSSH version) & Patients & $\begin{array}{l}\text { 30-item disability/symptom } \\
\text { scale }\end{array}$ & $\begin{array}{l}\text { 5-response choices of each } \\
\text { item }\end{array}$ & Moderate & $38(95)$ \\
\hline SF-36 & Patients & $\begin{array}{l}\text { Physical function, social } \\
\text { function, emotional role, } \\
\text { physical role function, mental } \\
\text { health, energy, pain, general, } \\
\text { health perceptions }\end{array}$ & $\begin{array}{l}\text { Variety of scales, used as a } \\
\text { generic measure of health } \\
\text { status }\end{array}$ & Moderate & $40(100)$ \\
\hline
\end{tabular}

* DASH (JSSH version), Disability of the Arm, Shoulder and Hand, The Japanese Society of Surgery of the Hand version; SF-36, Short-Form-36

and Kannmon Medical Centre, Yamaguchi) agreed to participate in the study which was performed between December 2004 and December 2005. The inclusion criteria were the ability to read and write in Japanese in order to complete the questionnaires and a willingness to participate in the study. The protocol was approved by the ethics board of each hospital and informed consent was obtained from all the patients.

There were 23 men and 17 women with a mean age of 47 years (18 to 81 ). The diagnoses included 14 bone tumours $(35 \%)$ (five giant cell tumours of bone, four osteosarcomas, two Ewing's sarcomas, and three others) and 26 soft-tissue tumours (65\%) (12 malignant fibrous histocytomas, four synovial sarcomas, two liposarcomas, two desmoid tumours and six others). The tumours were located at the shoulder girdle in seven patients, the upper arm in eight, the elbow in seven, the forearm in ten, and the wrist and hand in eight. Of the 40 patients, 21 $(52.5 \%)$ were continuously free from disease, $16(40 \%)$ had no evidence of disease and three $(7.5 \%)$ had active disease. The mean period from surgery to assessment was 41 months (4 to 360 ). The operative procedures included reconstruction after resection of the tumour in 21 $(52.5 \%)$, resection without reconstruction in $12(30 \%)$ and amputation in seven $(17.5 \%)$ patients.

The Enneking scoring system ${ }^{2}$ and its Japanese version $^{12}$ were used to assess function. Categories within this system included pain, function, emotional acceptance, hand positioning, strength and manual dexterity with each having a maximum of five points representing normal or full function (Table I). The DASH questionnaire is designed to measure total functional disability of the upper limb with a score of 0 representing the least and 100 the most disability. The SF-36 is based on the definition of health of the World Health Organisation and has a broad content recommended for health-status measures from the patient's perspective. We used The Japanese Society of Surgery of the Hand version of the DASH score ${ }^{5}$ and the official Japanese version of the SF-36, version $2^{6,7}$ (Table II).

The Enneking score for each patient was completed by the surgeon as a part of the routine clinical examination. After the examination, the purpose of the study was explained to the patient and their participation was requested. If they were willing, they completed the questionnaires.

Statistical analysis. The scores were calculated for all three systems and analyses were performed using SPSS software version 13.0J (SPSS Inc., Chicago, Illinois).

The data obtained with the Enneking score and the DASH and SF-36 questionnaires were described in terms of the frequency distribution, the central tendency (the mean), spread (the SD and the range of responses) and the presence of a ceiling or floor effect. We assumed that more 
Table III. Spearman rank correlation coefficients of the Enneking score with the Disability of the Arm, Shoulder and Hand (DASH) and shortform-36 (SF-36) subscales with 95\% confidence interval in parentheses

\begin{tabular}{|c|c|c|c|c|c|c|c|}
\hline \multirow{2}{*}{$\begin{array}{l}\text { Instruments } \\
\text { Outcome measure }\end{array}$} & \multicolumn{7}{|c|}{ Patients } \\
\hline & \multicolumn{2}{|c|}{ All $(n=40)$} & \multirow{2}{*}{$\begin{array}{l}\text { p-value } \\
<0.001\end{array}$} & $\begin{array}{l}\text { With tumours located proximal } \\
\text { to the elbow }(n=18)\end{array}$ & \multirow{2}{*}{$\begin{array}{l}\text { p-value } \\
<0.001\end{array}$} & $\begin{array}{l}\text { With tumours located distal } \\
\text { to the forearm }(n=22)\end{array}$ & \multirow{2}{*}{$\begin{array}{l}\text { p-value } \\
0.007\end{array}$} \\
\hline DASH & $-0.79 *$ & $(-0.62$ to -0.88$)$ & & $-0.84^{*}(-0.65$ to -0.93$)$ & & $-0.64^{*}(-0.23$ to -0.86$)$ & \\
\hline \multicolumn{8}{|l|}{ SF-36 } \\
\hline Physical functioning & $0.46^{*}$ & (0.17 to 0.68$)$ & 0.003 & $0.40 \quad(0.00$ to 0.70$)$ & 0.069 & $0.58^{*}$ (0.14 to 0.83$)$ & 0.012 \\
\hline Role physical & $0.60^{*}$ & (0.35 to 0.77$)$ & 0.001 & $0.50^{*}(0.17$ to 0.79$)$ & 0.008 & $0.64^{*}(0.23$ to 0.86$)$ & 0.005 \\
\hline Body pain & -0.06 & $(-0.37$ to +0.26$)$ & 0.706 & $-0.08 \quad(-0.49$ to +0.35$)$ & 0.698 & $0.02 \quad(-0.47$ to +0.50$)$ & 0.937 \\
\hline General health & -0.02 & $(-0.34$ to +0.29$)$ & 0.876 & $-0.21 \quad(-0.58$ to +0.23$)$ & 0.353 & $0.03 \quad(-0.17$ to +0.70$)$ & 0.185 \\
\hline Vitality & 0.06 & $(-0.26$ to +0.37$)$ & 0.720 & $-0.02 \quad(-0.44$ to +0.41$)$ & 0.936 & $0.24 \quad(-0.28$ to +0.64$)$ & 0.362 \\
\hline Social functioning & $0.43^{*}$ & (0.14 to 0.66$)$ & 0.006 & $0.53^{*}(0.15$ to 0.78$)$ & 0.010 & $0.31 \quad(-0.21$ to +0.68$)$ & 0.232 \\
\hline Role emotional & $0.38^{\dagger}$ & (0.07 to 0.62$)$ & 0.017 & $0.34 \quad(-0.09$ to +0.67$)$ & 0.117 & $0.46 \quad(-0.02$ to +0.77$)$ & 0.061 \\
\hline Mental health & 0.10 & $(-0.22$ to +0.40$)$ & 0.551 & $-0.05 \quad(-0.46$ to +0.38$)$ & 0.838 & $0.19 \quad(-0.33$ to +0.61$)$ & 0.470 \\
\hline
\end{tabular}

$$
\text { * } p<0.01
$$

$+\mathrm{p}<0.05$

severely disabled individuals (those with a high score on the DASH questionnaire and a low score on the SF-36) would have a lower Enneking score. Spearman's rank correlation coefficients were used to determine the association between the Enneking score and the responses on the patient-completed functional questionnaires. Statistical significance was set at a $\mathrm{p}$-value $\leq 0.05$.

\section{Results}

Completeness of item responses. Of the 40 patients, ten $(25 \%)$ did not answer one or more items of the DASH questionnaire, (all omitting item 21 regarding sexual activity). Among them, two patients age 72 and 81 years, respectively did not respond to sufficient numbers of items to allow complete scoring of the DASH questionnaire. These patients were excluded from the validity study. Regarding the SF-36, three patients did not answer one of the 36 items but the SF-36 subscale could be calculated with an estimated value. There was no missing item in any of the Enneking scores since they were completed by medical staff (Table II).

Distribution of responses. The mean Enneking score was 72 (23 to 100$)$, the mean DASH score was 27 (10 to 100$)$, the mean SF-36 physical functioning subscale was 79 (10 to $100)$ and the mean SF-36 role physical subscale was $70(0$ to 100; Fig. 1). A ceiling effect but no floor effect was noted in association with the Enneking score and the SF-36 physical functioning subscale. A floor effect but no ceiling effect was noted in association with the DASH. Both ceiling and floor effects were shown in association with the SF-36 role physical subscale.

Validation. The Spearman rank correlation coefficient of the Enneking score to the DASH and the SF-36 subscales are shown in Table III. The Enneking score was shown to have a high negative correlation $(\mathrm{r}=-0.79, \mathrm{p}<0.001)$ with DASH and to have moderate positive correlation with the SF-36 physical functioning subscale $(\mathrm{r}=0.46, \mathrm{p}=0.003)$, the role physical subscale $(\mathrm{r}=0.60, \mathrm{p}<0.001)$, social func- tion $(\mathrm{r}=0.43, \mathrm{p}=0.006)$ and the role emotional subscale $(\mathrm{r}=0.38, \mathrm{p}=0.017)$. The correlations were shown for all patients irrespective of the location of their tumour.

\section{Discussion}

Our comparison of the Enneking score with the DASH and the SF-36 subscales as measures of post-operative outcome for 40 patients with sarcoma of the arm showed high and moderate correlations of the Enneking score with the DASH and SF-36 scores regardless of the location of the tumour. The correlation of the Enneking score with the well-established DASH and SF-36 scores supports its validity.

Since it was published in $1987^{1}$ and revised in $1993,{ }^{2}$ the Enneking scoring system has been widely accepted as a functional measure of the upper and lower limb in patients undergoing surgery for a tumour. It is unclear whether the measure was intended to describe and evaluate change in status and if the intent was to use the measure with groups and individuals. The only validation of the Enneking score relates to a study on sarcoma of the lower limb performed by Davis et al. ${ }^{8}$ They compared the Enneking score, the Toronto Extremity Salvage Score (TESS) ${ }^{3}$ and the SF-36 as measures of functional status. The TESS is a validated measure which was developed to evaluate physical disability in patients with sarcoma of the lower limb from the perspective of the patient. The authors indicated that the Enneking score was shown to have a moderate positive correlation with the TESS. The latter was also shown to have a high positive correlation with the physical function subscale of the SF-36 and to have moderate positive correlations with the social function and mental health subscales.

In the absence of a disease-specific and patient-based questionnaire to measure function of patients with a sarcoma of the upper limb, we chose the DASH and SF-36 scores to evaluate the construct validity of the Enneking score. The DASH questionnaire is a standardised instru- 


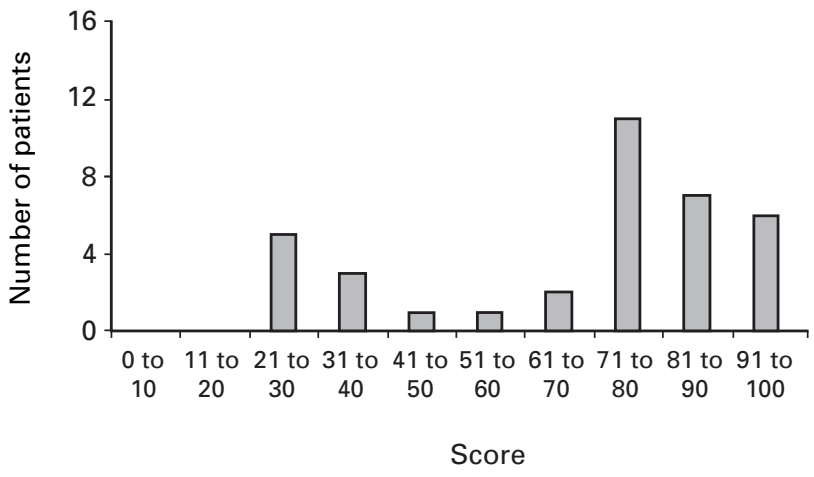

Fig. 1a

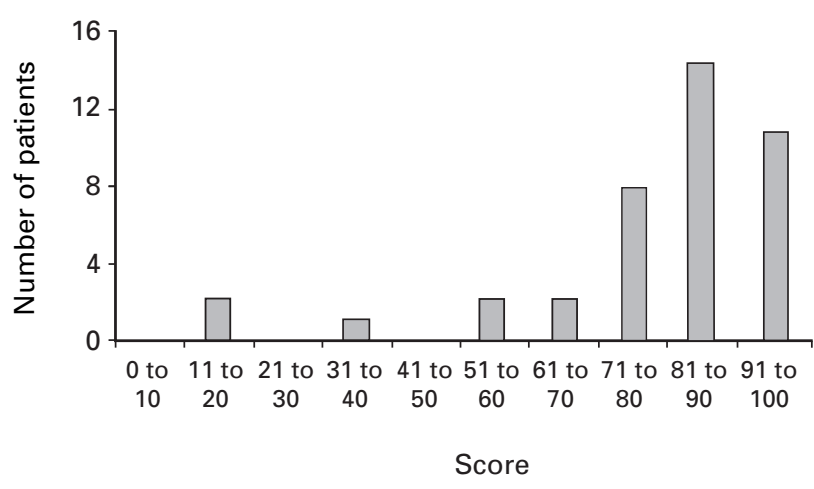

Fig. 1c

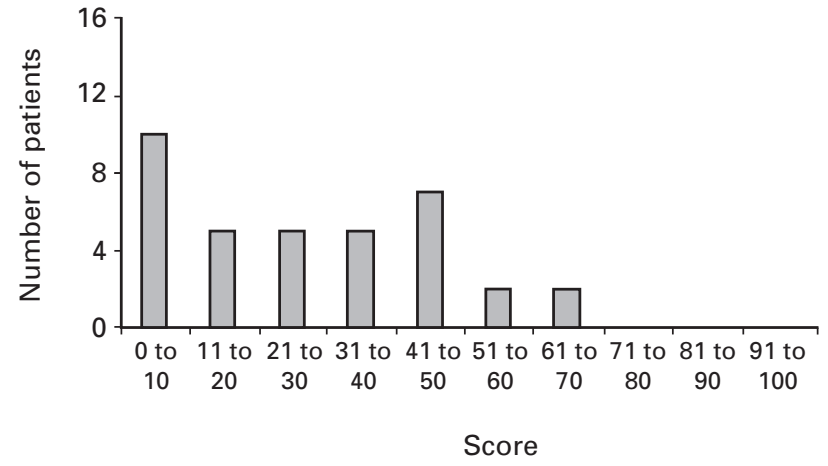

Fig. 1b

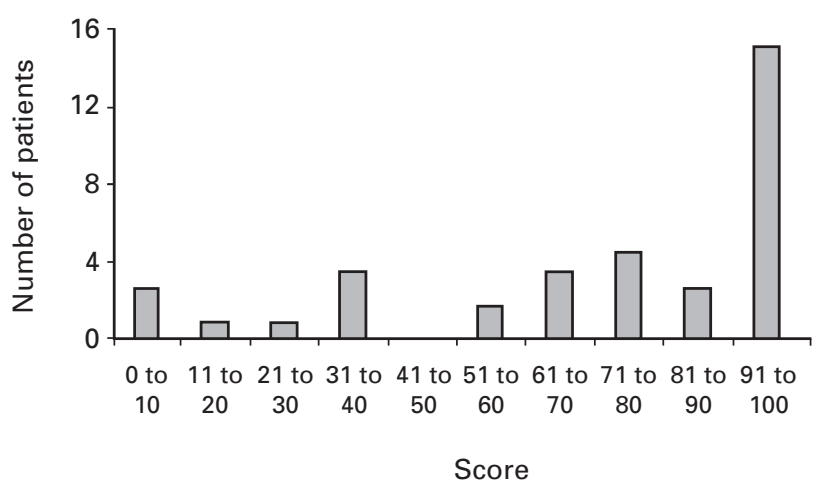

Fig. 1d

Barcharts showing a) the Enneking score, b) the Disability of the Arm, Shoulder and Hand, c) the short-form 36 (SF-36) physical function subscale anc d) the SF-36 role physical subscale for the 40 patients.

ment which measures the patient's own perspective of his/ her disability of the upper limb. It has been developed with careful attention to the psychometric principles of instrument design. The outcome measure can be reliable, can discriminate between severities of functional impact, can be sensitive to change over time, and can be statistically valid. ${ }^{5,8,13}$ The SF-36 score has been validated in patients with musculoskeletal complaints and is used widely for measuring health outcomes. However, it is a generic questionnaire and has the potential disadvantage of being less sensitive to clinical change in patients with complaints specific to an anatomical region or disease process. ${ }^{11,14,15}$

The correlation between disease- or region-specific outcome measures with the DASH and SF-36 scores has been evaluated. The correlation coefficient of -0.79 of the Enneking score with the DASH score was consistent with that seen in validation studies of outcome measures for the elbow and shoulder. Turchin, Beaton and Richards ${ }^{16}$ observed correlations of five observer-based elbow scoring systems and the DASH score ranging from 0.55 to 0.74 . Kirkley et $\mathrm{al}^{17}$ showed that the correlation coefficient between a disease-specific quality-of-life measurement tool for shoulder instability and the DASH score was 0.77. By contrast, that of the Enneking score with the SF-36 was consistent with that seen in validation studies of outcome measures for the shoulder and knee. Beaton and Richards ${ }^{13}$ observed correlations of five shoulder questionnaires with the SF-36 physical functioning and bodily pain subscales ranging from 0.58 to 0.72 .

The correlation between the Enneking and the DASH scores $(r=-0.79)$ was stronger than that between the Enneking and the SF-36 physical functioning $(r=0.46)$ and role physical $(\mathrm{r}=0.60)$ scores. This may have been due to the fact that the Enneking score and the DASH questionnaire enquire only about function and symptoms of the upper limb. Only three of ten items on the SF-36 physical functioning are devoted to the function of the arm.

In patient self-reported measures of outcomes, such as the DASH and SF-36, patients may not respond in sufficient numbers to certain items to allow complete scoring of the questionnaire. Indeed, two of the ten patients did not respond to sufficient numbers of items to allow complete scoring of their DASH questionnaires. The DASH and the SF-36 were also not developed for use with patients under the age of 16 or 17 years in whom osteosarcoma and Ewing's 
sarcoma occur frequently. The Enneking score is not limited by any age constraint.

The major limitation of our study is that the reliability of the Enneking score was not assessed because we performed a cross-sectional comparative study. Inter- and intraobserver reliability of the Enneking score also warrants investigation as was reported in a scoring system of foot and ankle disorders. ${ }^{18}$ Another potential limitation was our inclusion of more than one type of tumour and anatomical location in the arm. We did so to allow generalisation of the results to a wide variety of tumours and treatments of the upper limb.

Despite being a measure from the surgeon's perspective, the Enneking score has been shown to be a validated measure for evaluating physical disability of patients with sarcomas involving the upper limb which reflects their opinion. We propose that a patient-derived questionnaire to measure the functional status of patients with sarcoma of the upper limb could be developed from the Enneking score.

\section{Supplementary Material}

$\ddot{e}$ A further opinion by Mr S. R. Cannon is available with the electronic version of this article on our website at www.jbjs.org.uk

This work was supported by the Grant-in-Aid of Ministry of Health, Labour and Welfare.

No benefits in any form have been received or will be received from a commercial party related directly or indirectly to the subject of this article.

\section{References}

1. Enneking WF. Modification of the system for functional evaluation in the surgical management of musculoskeletal tumors. In: Enneking WF, ed. Limb salvage in musculoskeletal oncology. New York: Churchill Livingstone, 1987:626-39.

2. Enneking WF, Dunham W, Gebhardt MC, Malawar M, Pritchard DJ. A system for the functional evaluation of reconstructive procedures after surgical treatment of tumors of the musculoskeletal system. Clin Orthop 1993;286:241-6.
3. Davis AM, Wright JG, Williams Jl, et al. Development of a measure of physical function for patients with bone and soft tissue sarcoma. Qual Life Res 1996;5:508-16.

4. Hudak PL, Amadio PC, Bombardier C. Development of an upper extremity outcome measure: the DASH (disabilities of the arm, shoulder and hand): The Upper Extremity Collaborative Group (UECG). Am J Ind Med 1996;29:602-8.

5. Imaeda T, Toh S, Nakao Y, et al. Validation of the Japanese Society for Surgery of the Hand version of the Disability of the Arm, Shoulder, and Hand questionnaire. $J$ Orthop Sci 2005; 10:353-9.

6. Fukuhara S, Bito S, Green J, Hsiao A, Kurokawa K. Translation, adaptation, and validation of the SF-36 Health Survey for use in Japan. J Clin Epidemiol 1998:51:1037-44.

7. Fukuhara S, Ware JE Jr, Kosinski M, Wada S, Gandek B. Psychometric and clinical tests of validity of the Japanese SF-36 Health Survey. J Clin Epidemiol 1998;51:1045-53.

8. Davis AM, Beaton DE, Hudak $P$, et al. Measuring disability of the upper extremity: a rationale supporting the use of a regional outcome measure. J Hand Ther 1999;12:269-74.

9. SooHoo NF, McDonald AP, Seiler JG 3rd, McGillivary GR. Evaluation of the construct validity of the DASH questionnaire by correlation to the SF-36. J Hand Surg [Am] 2002;27:537-41.

10. Lingard EA, Katz JN, Wright RJ, et al. Validity and responsiveness of the Knee Society Clinical Rating System in comparison with the SF-36 and WOMAC. J Bone Joint Surg [Am] 2001;83-A:1856-64.

11. Martin DP, Engelberg R, Agel J, Swiontkowski MF. Comparison of the Musculoskeletal Function Assessment questionnaire with the Short Form-36, the Western Ontario and McMaster Universities Osteoarthritis Index, and the Sickness Impact Profile health-status measures. J Bone Joint Surg [Am]1997;79-A:1323-35.

12. The JOA Committee of Tumors. General rules of clinical and pathological studies on malignant bone tumours (in Japanese). Third ed. Tokyo: Kanahara-shuppan, 2000:54-5

13. Beaton DE, Richards RR. Measuring function of the shoulder: a cross-sectional comparison of five questionnaires. J Bone Joint Surg [Am] 1996;78-A:882-90.

14. Bessette L, Sangha O, Kuntz KM, et al. Comparative responsiveness of generic versus disease-specific and weighted versus unweighted health status measures in carpal tunnel syndrome. Med Care 1998;36:491-502.

15. Liang MH, Fossel AH, Larson MG. Comparisons of five health status instruments for orthopedic evaluation. Med Care 1990;28:632-42.

16. Turchin DC, Beaton DE, Richards RR. Validity of observer-based aggregate scoring systems as descriptors of elbow pain, function, and disability. J Bone Joint Surg [Am] 1998;80-A:154-62.

17. Kirkley A, Griffin S, McLintock H, Ng L. The development and evaluation of a disease-specific quality of life measurement tool for shoulder instability: The Western Ontario Shoulder Instability Index (WOSI). Am J Sports Med 1998;26:764-72.

18. Niki H, Aoki H, Inokuchi S, et al. Development and reliability of a standard rating system for outcome measurement of foot and ankle disorders. II: interclinician and intraclinician reliability and validity of the newly established standard rating scales and Japanese Orthopaedic Association rating scale. J Orthop Sci 2005;10:466-74. 